\title{
BUDAYA AUSTRONESIA DI KAWASAN DANAU SENTANI (Austronesian Culture in the Sentani Lake Area)
}

\author{
Hari Suroto \\ Balai Arkeologi Papua, Jalan Isele, Kampung Waena, Distrik Heram, Kota Jayapura 99358 \\ Telepon (0967) 572467, Faksimile (0967) 572467 e-mail: hariprimitiveart@gmail.com
}

\section{INFO ARTIKEL}

\section{Histori artikel}

Diterima: 15 Juli 2016

Direvisi: 5 Agustus 2016

Disetujui: 14 Oktober 2016

\section{Keywords:}

\section{Austronesian culture,}

Sentani,

cultural influence

Kata kunci:

budaya Austronesia,

Sentani,

pengaruh budaya

\begin{abstract}
Pottery artifacts distribution and language show that Austronesian speakers mostly settle, do activity, and interact with indigenous Papua in the coastal. Sentani Lake area is located in north part of Papua, in which Sentani language belongs to the non-Austronesian (phylum Trans New Guinea). This study is aimed to reveal the influence of Austronesian culture in Sentani Lake area through descriptive and qualitative methods. The data is gathered by conducting surface survey, environmental observation, and ethnoarchaeological approach. The influence of Austronesian culture in Sentani Lake area is brought through the coastal communities in Vanimo, Aitape, and East Sepik Papua New Guinea. Artifacts as the evidences showing the influence of Austronesian culture are in the form of pottery, glass bracelet, glass beads, and bronze artifacts. It is also shown through a pottery making tradition, tattoo, alcoholic drink, leadership system, and the breeding of dog, pig, and chicken.
\end{abstract}

\begin{abstract}
ABSTRAK
Persebaran artefak gerabah dan bahasa menunjukan penutur Austronesia lebih banyak bermukim, beraktivitas, dan berinteraksi dengan penduduk asli Papua di pesisir. Kawasan Danau Sentani terletak di pesisir utara Papua, bahasa Sentani tergolong dalam bahasa non-Austronesia (phylum Trans New Guinea). Tulisan ini bertujuan untuk mengetahui pengaruh budaya Austronesia di Kawasan Danau Sentani. Tulisan ini menggunakan metode deskriptif kualitatif. Metode pengumpulan data dilakukan dengan survei permukaan tanah serta pengamatan lingkungan, serta pendekatan etnoarkeologi. Pengaruh budaya Austronesia di Kawasan Danau Sentani melalui masyarakat pesisir di Vanimo, Aitape, dan Sepik Timur Papua Nugini. Artefak yang menjadi bukti pengaruh budaya Austronesia yaitu gerabah, gelang kaca, manik-manik kaca, artefak perunggu. Pengaruh lainnya yaitu tradisi pembuatan gerabah, tradisi tato, pembuatan minuman beralkohol, sistem kepemimpinan serta pemeliharaan anjing, babi dan ayam.
\end{abstract}

\section{PENDAHULUAN}

Danau Sentani merupakan danau yang terletak di Papua bagian utara, secara geografis terbentang dari timur ke barat sepanjang 26,5 kilometer, berbentuk seperti huruf $S$, dengan luas 9.635 hektar, lebar antara 0,75 6 kilometer. Terletak pada ketinggian $75 \mathrm{~m}$ dpl, tingkat kedalaman danau berkisar antara $6 \mathrm{~m}-140 \mathrm{~m}$, di danau ini terdapat 22 pulau. Sebelah selatan Danau Sentani, berupa perbukitan dan di sebelah utara yaitu pegunungan Cyclops [Dobonsolo (nama lokal)], yang menjadi batas danau dengan Samudera Pasifik.

Air Danau Sentani bersumber dari pegunungan Cyclops yang mengalir melalui Sungai Koyabu, Sungai Hubai, Sungai Makaole, Sungai Kleblouw, Sungai Taban, Sungai Klandili, dan Sungai Abeale. Sungaisungai ini dimanfaatkan oleh suku Sentani sebagai tempat mencari ikan, sebagai sumber air bersih, dan juga sebagai tempat memperoleh beberapa jenis batuan yang dapat dimanfaatkan untuk pembuatan kapak batu (tomako batu). 


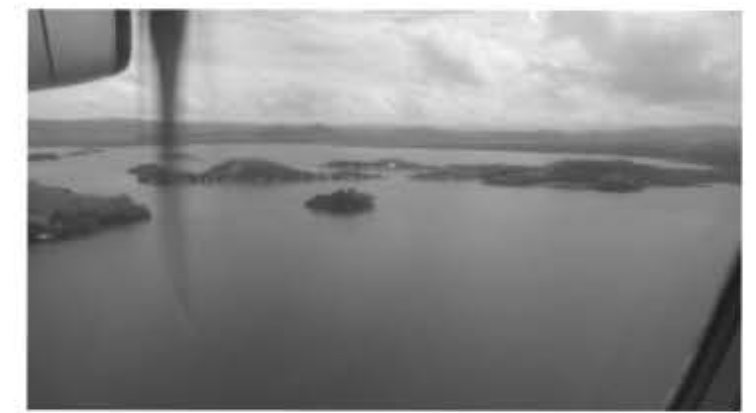

Gambar 1. Danau Sentani tampak dari atas (dokumentasi Hari Suroto)

Sungai Jaifuri yang terletak di sebelah timur danau, bermuara di Samudera Pasifik di perbatasan dengan Papua Nugini, selain itu Sungai Jaifuri menjadi penghubung antara penduduk kawasan Danau Sentani dengan masyarakat yang bermukim di pesisir Samudera Pasifik. Perahu besar (kayil perahu perempuan) dan perahu kecil (ifal perahu laki-laki) merupakan alat transportasi utama masyarakat Sentani.

Masyarakat Danau Sentani umumnya hidup di tepi danau maupun pulau yang terdapat di Danau Sentani, mereka hidup secara berkelompok membentuk perkampungan. Kampung-kampung di kawasan Danau Sentani yaitu Kampung Yoka, Waena, Sebeaiburu, Puay, Ayapo, Asei Kecil dan Asei Besar, Netar, Ifar Besar, Ifar Kecil (Ifale), Hobong, Yobhe, Yabuai, Putali, Abar, Atamali, Yoboi, Simporo, Babrongko, Dondai, Kwadeware, Yakonde, Sosiri, dan Doyo.

Konstruksi rumah masyarakat Sentani adalah rumah panggung, bagian muka rumah berada di darat, sedangkan bagian belakang rumah terletak di atas air. Tiang rumah menggunakan kayu soang (Xanthostemon sp.) tertancap di dasar danau, berdinding pelepah sagu, beratap daun sagu dan lantai papan dari batang sagu.
Pada 1500 hingga 1000 SM, datang imigran penutur Austronesia di Papua (Suroto, 2010:55). Kebudayaan dan teknologi penutur Austronesia sudah sangat maju. Mereka telah mengenal domestikasi ayam, anjing dan babi. Peralatan yang mereka buat dan gunakan berbahan cangkang moluska termasuk beliung, manikmanik, mata kail, gelang tangan dan terompet. Organisasi kemasyarakatan terstruktur dengan sistem hirarki, para pemimpinnya dijabat secara turuntemurun (Muller, 2008:53). Mengunyah pinang dan tato adalah ciri budaya Austronesia (Bellwood, 2000:199). Penutur Austronesia juga membawa budaya rumah panggung (Soejono, 1998:11), pembuatan minuman beralkohol hasil sadapan aren (Sacerifera), kelapa (Cocos nucifera) (Suroto, 2010:55).

Penutur Austronesia awal telah membuat gerabah serta memelihara, babi, anjing, dan ayam. Unsurunsur seperti itu terdapat secara luas di kepulauan Indonesia setelah kira-kira 4000 tahun yang lalu dan sebelumnya sama sekali tidak ada. Hal tersebut dapat dijadikan bukti untuk menunjukkan kehadiran penutur Austronesia, meskipun masih terlalu awal untuk ditarik kesimpulan dalam mengenali dan menggali keberadaan penutur Austronesia di Papua (Bellwood, 2000:169). Berdasarkan persebaran artefak gerabah dan bahasa, penutur Austronesia lebih banyak bermukim, beraktivitas, dan berinteraksi dengan penduduk asli Papua di pesisir (Suroto, 2010:43).

Berdasarkan uraian di atas, diketahui bahwa pengaruh budaya Austronesia lebih banyak di pesisir utara Papua. Kawasan Danau Sentani terletak di Papua bagian utara, bahasa Sentani tergolong dalam 
bahasa non-Austronesia (phylum Trans New Guinea). Hal ini sangat menarik, apakah budaya Austronesia juga terdapat di kawasan Danau Sentani? Apakah masyarakat Sentani melakukan hubungan langsung dengan penutur Austronesia? Tulisan ini akan membahas pengaruh budaya Austronesia di Kawasan Danau Sentani. Tulisan ini digunakan metode deskriptif kualitatif. Metode pengumpulan data dilakukan dengan survei permukaan tanah serta pengamataan lingkungan sekitar situs untuk mendapatkan data arkeologi dalam konteks dengan lingkungan, dan untuk mengetahui hubungan antardata arkeologi (Redaksi, 2008:22), serta pendekatan etnoarkeologi.

\section{PEMBAHASAN}

Kehadiran budaya Austronesia di kawasan Danau Sentani, berawal dari hasil penelitian arkeologi yang menunjukkan bahwa artefak gerabah ditemukan di situs-situs arkeologi pada permukaan maupun di dalam tanah, baik di situs terbuka dan situs gua. Situs terbuka yang terdapat gerabah yaitu Situs Yomokho, Kwadeware, Abar, Phulende dan Mantai. Situs gua yang terdapat artefak gerabah yaitu Gua Rukhabulu Awabhu, Ceruk Reugable, dan Ceruk Ifeli-feli. Artefak gerabah ini berkonteks cangkang siput danau (Thiaridae) dan cangkang moluska laut kelas bivalvia famili veneridae.

Situs Yomokho sebagai tempat komunitas manusia beraktivitas berlangsung pada $2590 \pm 120 \mathrm{BP}$. Pemukiman terbuka dengan rumah panggung, berada di lereng-lereng bukit. Hunian diatas bukit, lebih strategis dari segi keamanan, dan terhindar dari serangan malaria. Hasil ekskavasi di Situs Yomokho menunjukkan bahwa gerabah digunakan sebagai wadah untuk memasak, menyimpan makanan dan bekal kubur. Motif gerabah situs Yomokho yaitu garis zigzag, wavy, dotted, dan diagonal serta sebagian diberi slip merah. Aktivitas manusia di Situs Yomokho berdasarkan pertanggalan ini sesuai dengan kehadiran penutur Austronesia di Pasifik barat pada 3000 tahun yang lalu.

Pola hias gerabah dari Situs Kwadeware memiliki kesamaan dengan gerabah dari Gua Skouw Mabo Jayapura, Gua Lachitu dan Gua Taora di Vanimo Papua Nugini. Gorecki (1992:35) menyatakan bahwa gerabah dari Gua Lachitu dan Gua Taora memiliki pertanggalan 5400 tahun yang lalu, tetapi beberapa peneliti menyangsikan pertanggalan yang dilakukan Gorecki dan mereka percaya pertanggalannya lebih muda (Simanjuntak, 1997:944).

Memasak menggunakan gerabah tidak dikenal di daerah Papua yang penduduknya menuturkan bahasa non-austronesia terkecuali Sentani. Gerabah sangat penting bagi suku Sentani yang hidup dari mengolah sagu (Metroxylon sago) dan mengkonsumsi ikan dan moluska danau. Satusatunya daerah penghasil gerabah di kawasan Danau Sentani adalah Abar. Gerabah di Abar dibuat dari tanah liat dicampur pasir. Teknik pembuatannya yaitu gabungan teknik pijit dan spiral. Penyelesaian permukaan gerabah dengan teknik upam. Permukaan gerabah diberi hiasan dengan teknik tempel, tera, gores dan tusuk. Gerabah dibakar di tempat terbuka, sehingga menghasilkan warna merah atau coklat yang tidak merata. Gerabah ini juga berfungsi sebagai alat tukar. Gerabah ditukar dengan manik-manik, kapak batu, atau bahan makanan. 


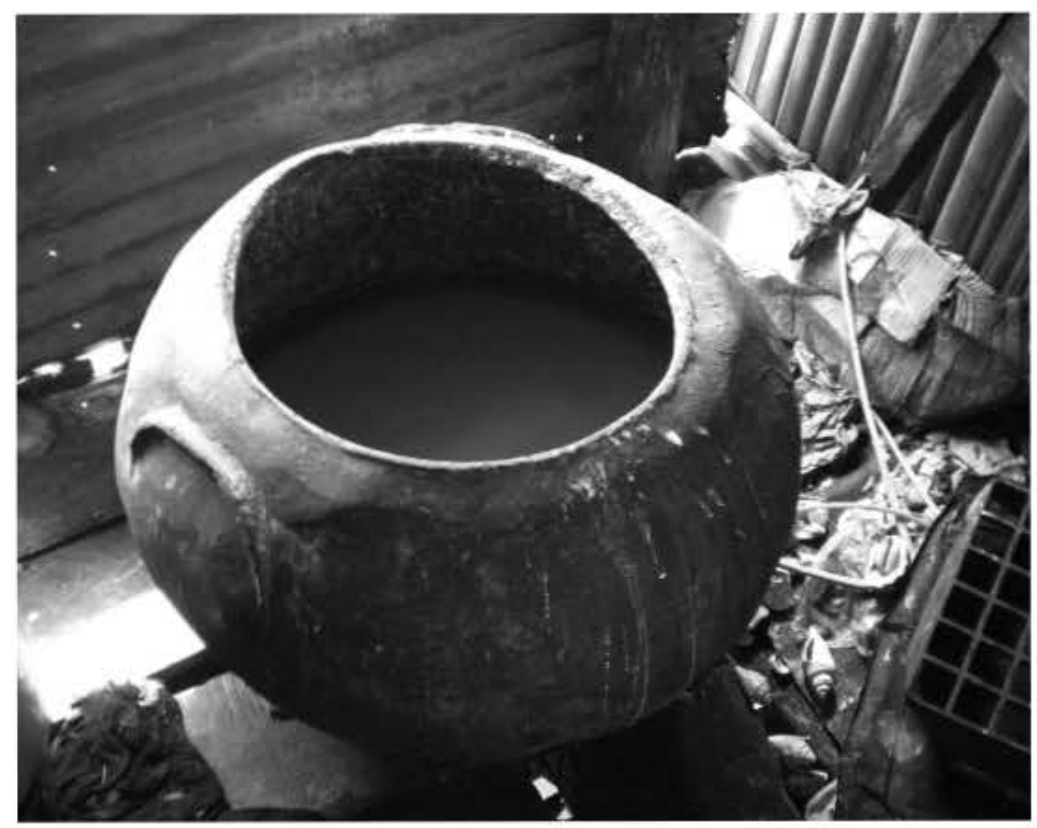

kecantikan, dan status sosial seseorang. Oleh karena itu, jenis dan bentuk tato tergantung pada status sosial (ondofolo/pemimpin adat tertinggi, kotelol kepala suku, dan yobu yoholom/ masyarakat kebanyakan) dan jenis kelamin. Tato ini dibuat dengan menggunakan duri sagu atau duri umbi berkulit keras. Duri dicelupkan ke dalam campuran getah dan arang, kemudian Gambar 2. Hele (dokumentasl Balal Arkeologl Papua)

ditusukkan pada bagian tubuh yang hendak ditato. Corak tato laki-laki Tempayan berukuran besar dalam bahasa Sentani disebut dengan istilah hele. Berfungsi sebagai wadah menyimpan air dan untuk menyimpan tepung sagu. Helai yaitu tempayan kecil untuk memasak, merebus air dalam proses pembuatan bubur sagu (papeda), menyimpan ikan dan daging. Olomebe merupakan sejenis tempayan yang khusus untuk memasak ikan (gabus hitam [kayaou (nama lokal), Oxyeleotoris herwedinit], gete-gete [kahe (nama lokal), Apogon wichman], puri danau [hew (nama lokal), Chilaterina sentaniensis], belut [kahilo (nama lokal), Aguilla bicolor)], ikan sembilan [kansell (nama lokal), Arius veluntinus)] dan siput air tawar (Thiara scabra, Melanoides tuberkulata, Melanoides canalis, Stelomelania sp., Melanoides granifera, Melanoides copalis, dan Malanoides sentaniensi). Kende adalah piring tanah liat, bentuknya lonjong seperti piring kayu. Kende ini digunakan sebagai tempat menghidangkan daging atau ikan yang telah siap untuk dimakan.

Suku Sentani mengenal perhiasan tato pada wajah, tangan, dan Sentani lebih sederhana pada hidung dan dahi. Perempuan mempunyai tato yang lebih bercorak kompleks pada dahi, punggung, lengan, dan betis. Desain tato biasanya berbentuk pecahan ornamen, gambar binatang, dan lambang. Desain tato pun bergantung pada luas sempitnya bagian tubuh yang hendak ditato, misalnya, tato di hidung akan mengikuti bentuk hidung (Yektiningtyas-Modouw, 2008:63).

Masyarakat Sentani mengenal pembuatan seguer yaitu minuman tradisional beralkohol dari nira kelapa. Saguer ini berupa cairan putih dengan rasa manis keasam-asaman dan mengandung alkohol sekitar lima persen. Untuk memperoleh saguer, wadah bambu diberi saringan ijuk palem, digantung pada bagian batang bunga kelapa yang telah dipotong untuk menampung saguer.

Tradisi mengunyah pinang (Areca catechu), yang dikombinasikan dengan buah sirih (piper bette), dan bubuk kapur sangat popular bagi suku Sentani. Pinang bagi suku Sentani

kaki. Tato adalah simbol kekuasaan, 
merupakan simbol rasa hormat dan menjadi media dalam menjalin hubungan baik satu dengan yang lainnya. Kapur terbuat dari cangkang moluska laut dan kapur dari cangkang moluska danau (kelas Bivalvia famili Veneridae, [kheka (nama lokal)]. Kapur yang terbuat dari cangkang moluska danau lebih disukai, berwarna putih keabu-abuan dan efek mulut terbakar tidak begitu kuat. Sedangkan kapur berbahan cangkang moluska laut berwarna putih bersih dan mempunyai efek mulut terbakar yang lebih kuat.

Cangkang moluska laut diperoleh dari perairan Samudera Pasifik. Cangkang moluska jenis kheka dikumpulkan dari danau. Proses pembuatan kapur yaitu daun sagu kering disusun menjadi satu lapis di atas permukaan tanah. Cangkang moluska kemudian ditaruh di atas lapisan daun sagu kering. Selanjutnya di atas lapisan cangkang moluska diletakkan lapisan daun sagu kering. Jumlah lapisan daun sagu kering menyesuaikan dengan jumlah cangkang moluska yang akan dibakar. Tumpukan lapisan cangkang moluska dan daun sagu kering kemudian diikat dan dibakar, proses pembakaran dimulai dari lapisan atas. Setelah pembakaran selesai, cangkang moluska yang masih panas dikumpulkan dalam wadah dan disiram air. Cangkang moluska yang terkena air akan hancur dengan sendirinya menjadi bubuk kapur. Serbuk kapur ini kemudian ditapis, dan siap digunakan. Secara tradisional bubuk kapur disimpan dalam wadah terbuat dari tempurung kelapa kering yang diukir atau dilukis.

Suku Sentani mengenal sistem kepemimpinan ondoafi, yaitu organisasi kemasyarakatan yang terstruktur dengan sistem hirarki pemimpinnya dijabat secara turun-temurun.
Pemimpin dipegang oleh anak sulung dari pemimpin sebelumnya, berasal dari klen yang paling senior (nenek moyang pendiri).

Babi (Sus Scrofa Papuensis) dipelihara dan sangat bernilai bagi masyarakat Sentani. Babi dipelihara dalam jumlah sedikit, sekitar tiga atau empat ekor, dan dibiarkan bebas berkeliaran di sekitar rumah. Babi diberi makan daun ubi jalar, kangkung, kelapa, dan batang pohon sagu. Daging babi disajikan sebagai hidangan utama dalam pesta-pesta biasa dan berbagai ritual tradisional Sentani. Bagi masyarakat Sentani, yang berhak untuk membagi daging babi pada suatu acara tertentu adalah kepala suku.

Penutur Austronesia yang bermigrasi ke Pasifik beradaptasi dengan lingkungan sekitar, meninggalkan kegiatan bercocok tanam padi, mengkonsumsi tanaman lokal seperti sukun (Artocarpus altilis), keladi (Colocasia esculenta), pisang (Australimusa), kelapa, tebu (Saccharum Officinarum L., Saccharum Spotaneum L., Saccharum Robustus Brandes Jeswiet) dan sagu, mencari hasil laut dan melakukan pertukaran dengan penduduk lokal. Komoditas yang dijadikan barter adalah benda eksotis (artefak perunggu, manikmanik, gelang kaca) ditukar dengan burung eksotis cenderawasih (Paradisaea minor) (Suroto, 2010:56).

Artefak perunggu ditemukan di kawasan Danau Sentani (Bellwood, 1978:266), manik-manik kaca, gelang kaca ditemukan di situs arkeologi maupun disimpan oleh masyarakat Sentani. Hingga saat ini ketiga jenis benda tersebut sangat dihargai dan bernilai tinggi oleh suku Sentani, sebagai roboni (mas kawin). 


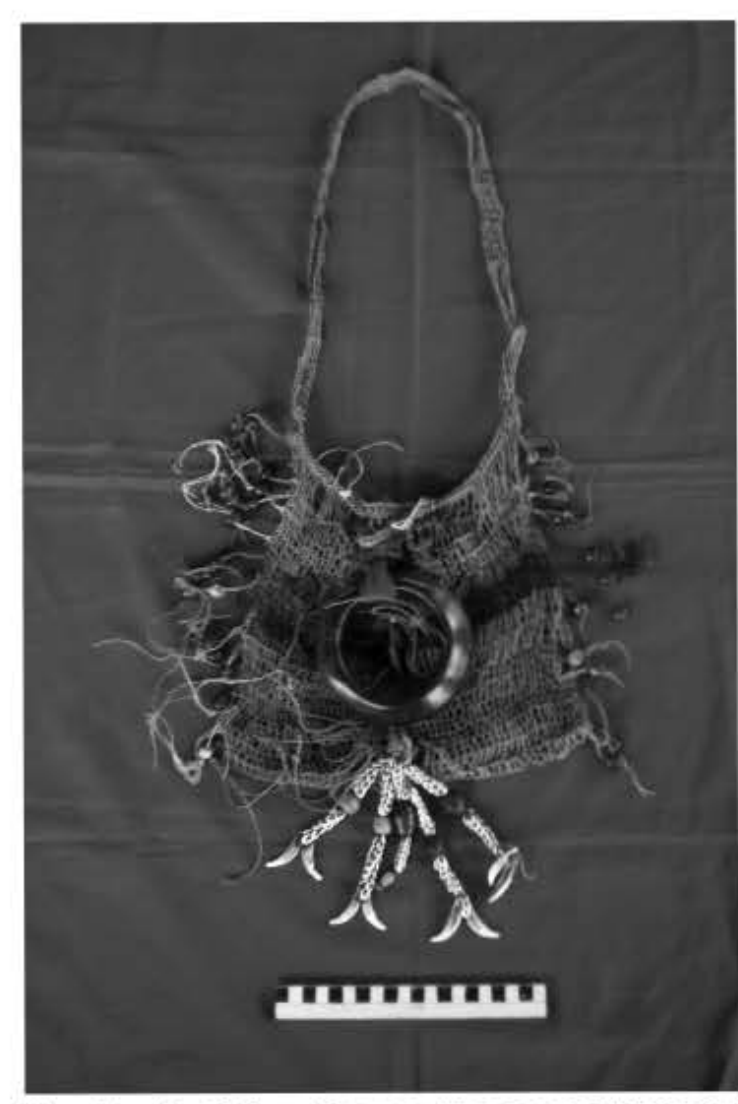

Gambar 3. Noken dengan hlasan manlk-manlk dan gelang kaca (dokumentasi Hari Suroto)

Artefak manik-manik kaca wama putih ditemukan dalam ekskavasi di situs Yomokho. Manikmanik kaca warna hitam ditemukan di situs Phulende. Artefak perunggu ditemukan di Kwadeware berupa mata kapak berbentuk convex yang melebar pada bagian tajamannya (Tim penelitian, 2010:18). Pada salah satu bidang datar kapak mempunyai hiasan berbentuk spiral yang tersusun melingkari sebuah titik yang menonjol sebagai pusat bidang gambar. Kapak perunggu ini saat ini disimpan oleh ondofolo Kwadeware. Kondisi kapak perunggu ini mulai aus, motif hiasnya sudah pudar. Jika dilihat dari bentuk dan motif hiasnya, kapak ini dibuat bukan untuk keperluan praktis tetapi untuk kepentingan religius atau sosial. Bagi masyarakat Kwadeware, kapak ini merupakan salah satu mas kawin bagi keluarga ondofolo Kwadeware.
Cerita rakyat Sentani menyebutkan nenek moyang Sentani berasal dari Sepik Timur, Papua Nugini. Mereka bermigrasi menuju ke arah barat, tiba dan menetap di Danau Sentani. Hal ini sesuai dengan cerita pemilik gelang kaca, dan manik-manik kaca bahwa kedua jenis artefak ini ini dibawa oleh leluhur sewaktu mereka datang dari timur ke barat. Diperkirakan bahwa artefak kaca ini berasal dari timur, karena Vanimo dan Aitape juga mengenal budaya pemakaian artefak gelang kaca dan manik-manik kaca ini.

Hal yang sangat berbeda adalah cerita rakyat Vanimo yang menyebutkan bahwa nenek moyang mereka dari kawasan Danau Sentani. Berdasarkan dua versi cerita rakyat ini dapat menggambarkan bahwa, masyarakat Vanimo dan Sentani memiliki hubungan historis. Selain dibuktikan dengan keberadaan artefak gelang kaca dan manik-manik kaca, juga keberadaan sisa makanan berupa cangkang moluska laut di situs-situs arkeologi kawasan Danau Sentani, serta cangkang moluska laut merupakan bahan utama dalam pembuatan bubuk kapur, membuktikan bahwa masyarakat Sentani telah melakukan hubungan dengan masyarakat pesisir pantai (Vanimo, Aitape, Sepik timur).

Asal usul budaya Austronesia di kawasan Danau Sentani merupakan hal yang menarik untuk mengkaji asal usulnya. Berdasarkan bukti linguistik bahwa bahasa Sentani adalah nonAustronesia, maka diperkirakan masyarakat Sentani tidak berhubungan langsung dengan penutur Austronesia, tetapi hubungan secara tidak langsung melalui masyarakat Vanimo, Aitape, dan Sepik timur. 


\section{PENUTUP}

Pengaruh budayaAustronesia di kawasan Danau Sentani berdasarkan penelitian arkeologi maupun etnoarkeologi yaitu artefak gerabah, gelang kaca, manik-manik kaca, artefak perunggu, tradisi pembuatan gerabah, tradisi tato, pembuatan minuman beralkohol dari pohon kelapa, sistem kepemimpinan yang diwariskan secara turun temurun serta pemeliharaan anjing, babi dan ayam. Kehadiran budaya Austronesia di Kawasan Danau Sentani, bukan karena kontak langsung kedua komunitas tersebut, tetapi kontak tidak langsung melalui masyarakat pesisir di Vanimo, Aitape, dan Sepik Timur Papua Nugini. 


\section{DAFTAR PUSTAKA}

Bellwood, Peter. 1978. Man's Conquest of The Pacific The Prehistory of Southeast Asia and Oceania. Aucland: Collins.

Bellwood, Peter. 2000. Prasejarah Kepulauan Indo-Malaysia. Jakarta: PT Gramedia Pustaka Utama.

Gorecki, P. 1992. "A Lapita smoke screen?", Actes du Colloque Lapita. ORSTOM: Noumea. HIm. 27-47.

Muller, Kal. 2008. Introducing Papua. Daisy World Books.

Redaksi. 2008. Metode Penelitian Arkeologi. Jakarta: Pusat Penelitian dan Pengembangan Arkeologi Nasional.

Simanjuntak, Harry Truman. 1997. "Revieuw of the prehistory of Irian Jaya" dalam Jelle Miedema, Cecilia Ode dan Rien A.C. Dam (ed.), Perspectives on the Bird's Head of Irian Jaya, Indonesia. Proceedings of the Conference Leiden, 13-17 October 1997. HIm. 941-950.

Soejono, R.P. 1998. "Indonesia dalam lingkup Prasejarah Asia Tenggara dan Pasifik" dalam Dinamika Budaya Asia Tenggara-Pasifik dalam Perjalanan Sejarah. DIAX Bandung 1997. IAAI komda Jawa Barat. HIm. 9-12.

Suroto, Hari. 2010. Prasejarah Papua. Denpasar: Udayana Universiy Press.

Tim Penelitian. 2010. Penelitian Arkeologi di Kawasan Danau Sentani. Laporan Penelitian Balai Arkeologi Jayapura.

Yektiningtyas-Modouw, Wigati. 2008. Helaehili dan Ehabla. Fungsinya dan Peran Perempuan dalam Masyarakat Sentani Papua. Yogyakarta: Adicitra Karya Nusa. 